ARTICLE

\title{
A host-guest semibiological photosynthesis system coupling artificial and natural enzymes for solar alcohol splitting
}

\author{
Junkai Cai ${ }^{1}$, Liang Zhao ${ }^{1 凶}$, Cheng $\mathrm{He}^{1}$, Yanan $\mathrm{Li}^{1} \&$ Chunying Duan ${ }^{1 凶}{ }^{1 凶}$
}

Development of a versatile, sustainable and efficient photosynthesis system that integrates intricate catalytic networks and energy modules at the same location is of considerable future value to energy transformation. In the present study, we develop a coenzyme-mediated supramolecular host-guest semibiological system that combines artificial and enzymatic catalysis for photocatalytic hydrogen evolution from alcohol dehydrogenation. This approach involves modification of the microenvironment of a dithiolene-embedded metal-organic cage to trap an organic dye and NADH molecule simultaneously, serving as a hydrogenase analogue to induce effective proton reduction inside the artificial host. This abiotic photocatalytic system is further embedded into the pocket of the alcohol dehydrogenase to couple enzymatic alcohol dehydrogenation. This host-guest approach allows in situ regeneration of NAD $+/ \mathrm{NADH}$ couple to transfer protons and electrons between the two catalytic cycles, thereby paving a unique avenue for a synergic combination of abiotic and biotic synthetic sequences for photocatalytic fuel and chemical transformation.

\footnotetext{
${ }^{1}$ State Key Laboratory of Fine Chemicals, Zhang Dayu School of Chemistry, Dalian University of Technology, Dalian, People's Republic of China.

凶email: zhaol@dlut.edu.cn; cyduan@dlut.edu.cn
} 
A biotic-biotic hybrid systems that combine light-driven artificial catalysis with biosynthetic enzymes at the same location have emerged as attractive and versatile avenues for light-trap fuel and chemical transformation with high efficacy and selectivity ${ }^{1-5}$. Recent advances have demonstrated that coupling solar fuel synthesis with value-added dehydrogenation may enhance economic and environmental benefits sans the expense of sacrificial reagents, while avoiding the harsh conditions required for the reforming processes ${ }^{6,7}$. Ethanol is a promising hydrogen storage chemical that can be effectively dehydrogenated by alcohol dehydrogenase $(\mathrm{ADH})$ with the assist of coenzymes ${ }^{8,9}$. However, due to the inherent two-electron reduction characteristic $^{10,11}$, the use of NADH (reduced nicotinamide adenine dinucleotide) to mediate artificial photoinduced proton reduction with enzymatic conversions remains a steep challenge in homogeneous system due to issues related to kinetic synergy and catalytic compatibility ${ }^{12,13}$. Precise matching of the kinetics of multiple electron transfer steps between abiotic and biotic components is a prerequisite to restrain the competitive reaction of $\mathrm{NADH}$ radical aggregation with photosensitizer radicals or itself ${ }^{14,15}$

Consequently, the integration of photosensitizer, coenzyme, and catalyst into one working module via the host-guest approach is promising to co-localize the essential components within the catalytic pocket of $\mathrm{ADH}$ and manipulate biomimetic catalysis at the molecular level ${ }^{16-18}$. Of the reported artificial supramolecular catalysts, metal-organic cages are superficially reminiscent of enzymes by modulating the microenvironment to accommodate and interact with substrates ${ }^{19-23}$. Dye-containing metal-organic cages exhibit profound effects in regulating and promoting the light-driven hydrogen evolution and related hydrogenation 24,25 . Incorporation of dye-containing metalorganic cages into the $\mathrm{ADH}$ catalytic pocket was expected to eliminate inherent communication barriers as well as mutual inactivation between the abiotic and biotic systems and promote the delivery of matters and energy, thereby facilitating the combination of $\mathrm{NAD}^{+}$-mediated dehydrogenation and $\mathrm{NADH}$ modified hydrogen evolution ${ }^{12,13,26,27}$. Successful realization of paradigmatic structural fitness and kinetic compatibility requires careful orchestration of organic dye encapsulated by a potentialmatching redox-active metal-organic cage for inclusion into the $\mathrm{ADH}$ catalytic pocket in a matryoshka fashion ${ }^{26,27}$.

Here, we report a cobalt dithiolene-embedded pillared cage capable of trapping the shape and size matching photosensitizer and the coenzyme NADH as the middle layer of matryoshka, thereby combining abiotic photocatalytic hydrogen production with biotic dehydrogenation of alcohol within the $\mathrm{ADH}$ catalytic pocket (Fig. 1). The coexistence of the planar dye, 2-phenyl-4-(1naphthyl)-quinolinium (PNQ $)^{28}$, and the coenzyme NADH, within one redox-active microenvironment can enforce close proximity between these components to enhance the efficacy of photoinduced electron transfer inside metal-organic cage ${ }^{29,30}$, while simultaneously allowing efficient photocatalytic hydrogen production to directly produce $\mathrm{NAD}^{+}$in analog to the natural hydrogenase $^{31}$. While situated inside the $\mathrm{ADH}$ catalytic pocket, the coenzyme is in direct contact with two catalytic cycles in situ, which enables it to maintain a closed loop of electrons and protons, thereby allowing the formation of a versatile redoxneutral photosynthesis system to actuate a non-photoactive natural enzyme for solar chemical conversion.

\section{Results}

Preparation and characterization of the metal-organic cage. The tripodal tris(benzene- $o$-dithiol) ligand with rich $\pi$-electron plane, $\mathrm{H}_{6}$ TPS ( $N, N^{\prime}$-(5'-(4-(2,3- dimercaptobenzamido)phenyl)- $\left[1,1^{\prime}: 3^{\prime}, 1^{\prime \prime}\right.$-terphenyl]-4,4" -diyl)bis(2,3-dimercaptoben-zamide)), was synthesized through amide condensation of freshly prepared 2,3-bis(isopropylthio)benzoyl chloride and 1,3,5-tris(4-aminophenyl) benzene, followed by removal of the protecting groups (Supplementary Fig. 1). The reaction of $\mathrm{H}_{6}$ TPS and $\mathrm{Co}\left(\mathrm{BF}_{4}\right)_{2} \cdot 6 \mathrm{H}_{2} \mathrm{O}$ in $N, N$-dimethylformamide (DMF) solution containing $\mathrm{NaOH}$ and $\mathrm{NEt}_{4} \mathrm{Cl}$ yielded $51 \%$ of the blue compound $\mathrm{Co}_{3} \mathbf{T P S}_{2}$, implying the formation of cobalt dithiolene-embedded molecular cage (Fig. 1) ${ }^{32}$. Installing cobalt dithiolene species on the metal-organic cage was expected to endow the artificial host with negative charge while maintaining superior redox activity with a desired low overpotential ${ }^{33,34}$, which was essential for $\mathrm{Co}_{3} \mathrm{TPS}_{2}$ to create a redox microenvironment in analog to hydrogenase and firmly bind the positively charged photosensitizer through its pocket to form host-guest species ${ }^{32}$. Singlecrystal X-ray structural analysis of $\mathrm{Co}_{3} \mathbf{T P S}_{2}$ revealed that the redox-active cobalt dithiolene species were recast to form a molecular anionic triangular prism cage with a pseudo- $C_{3}$ symmetry matching well with the optimal geometrical structures by theoretical calculations (Fig. 2a, b and Supplementary Figs. 2, 33). Two deprotonated $\mathrm{H}_{6}$ TPS molecules bonded three cobalt ions forming a pillared host with three cobalt dithiolene cores, in which all sulfur and cobalt atoms were in one plane. The average Co-S bond distance of approximately $2.15 \AA$ was in good agreement with the reported cobalt dithiolene species, implying that the cobalt dithiolene core retained its original redox activity after modification on the metal-organic cage (Supplementary Tables 1 and 2) $)^{32,33}$. Two triphenyl benzene groups, located on the top and the bottom of the triangular prism $\mathrm{Co}_{3} \mathbf{T P S}$, built a box-shaped cavity with a height of $\sim 8.57 \AA$, wherein the negatively charged cobalt dithiolene cores were positioned at the midpoint of each edge with a Co $\cdots$ Co separation of $\sim 18.66 \AA$ and yielded a diameter of $\sim 23.10 \AA$. This pillared cage containing two parallel aromatic planes provided an appropriate shape for encapsulating planar photosensitizer via aromatic stacking in a face-to-face way ${ }^{35,36}$. The amide groups which were located on the three triangular planes provided static, geometric, and functional properties to the cage, thereby enabling the metal-organic cage to attract electron donor via peripheral binding with a pocket-bound photosensitizer to form an integrated supramolecular assembly $32,37,38$

${ }^{1} \mathrm{H}$ NMR spectra displayed a single set of ligand related signals relative to a highly symmetrical complex, where a diffusionordered NMR spectrum confirmed the formation of a single species with a single diffusion coefficient of $8.6 \times 10^{-11} \mathrm{~m}^{2} \mathrm{~s}^{-1}$ and an estimated diameter of $23.40 \AA$ based on the Stokes-Einstein equation consistent with the results determined by the crystal structure (Supplementary Fig. 4) ${ }^{39,40}$. The ESI-MS spectrum of the $\mathrm{Co}_{3}$ TPS $_{2}$ exhibited two intense peaks at $m / z=625.6254$ and 949.9336 assigned to $\left[\mathrm{Na}_{3-n} \mathrm{Co}_{3}(\text { TPS })_{2}\right]^{n-}(n=2,3)$ via a comparison with the simulation results based on natural isotopic abundances (Supplementary Fig. 3), demonstrating the high stability of the cage in DMF solution and the trivalent cobalt ions on $\mathrm{Co}_{3} \mathbf{T P S}_{2}$. There was the same outcome in the mixed solvent of $\mathrm{EtOH} / \mathrm{H}_{2} \mathrm{O}(3: 2)$, showing the integrity of the triangular prism cage in a water-containing system.

Cyclic voltammetry of $\mathrm{Co}_{3}$ TPS $_{2}$ exhibited a suitable potential of $-0.58 \mathrm{~V}$ (vs. $\mathrm{Ag} / \mathrm{AgCl}$ ) assignable to the couple $\mathrm{Co}(\mathrm{III}) / \mathrm{Co}(\mathrm{II})$, which is in good agreement with previously reported cobalt dithiolene species and falls well within the range of that for proton reduction in aqueous solution (Fig. $3 \mathrm{a})^{33,41}$. The addition of trifluoroacetic acid triggered the emergence of a catalytic wave at approximately -0.75 and $-1.20 \mathrm{~V}$ (Supplementary Figs. 13 and 14). Moreover, the catalytic response for the proton reduction permitted a linear dependence on $\mathrm{Co}_{3} \mathbf{T P S}_{2}$ concentration with a half-wave potential of $-0.64 \mathrm{~V}$ in the presence of 


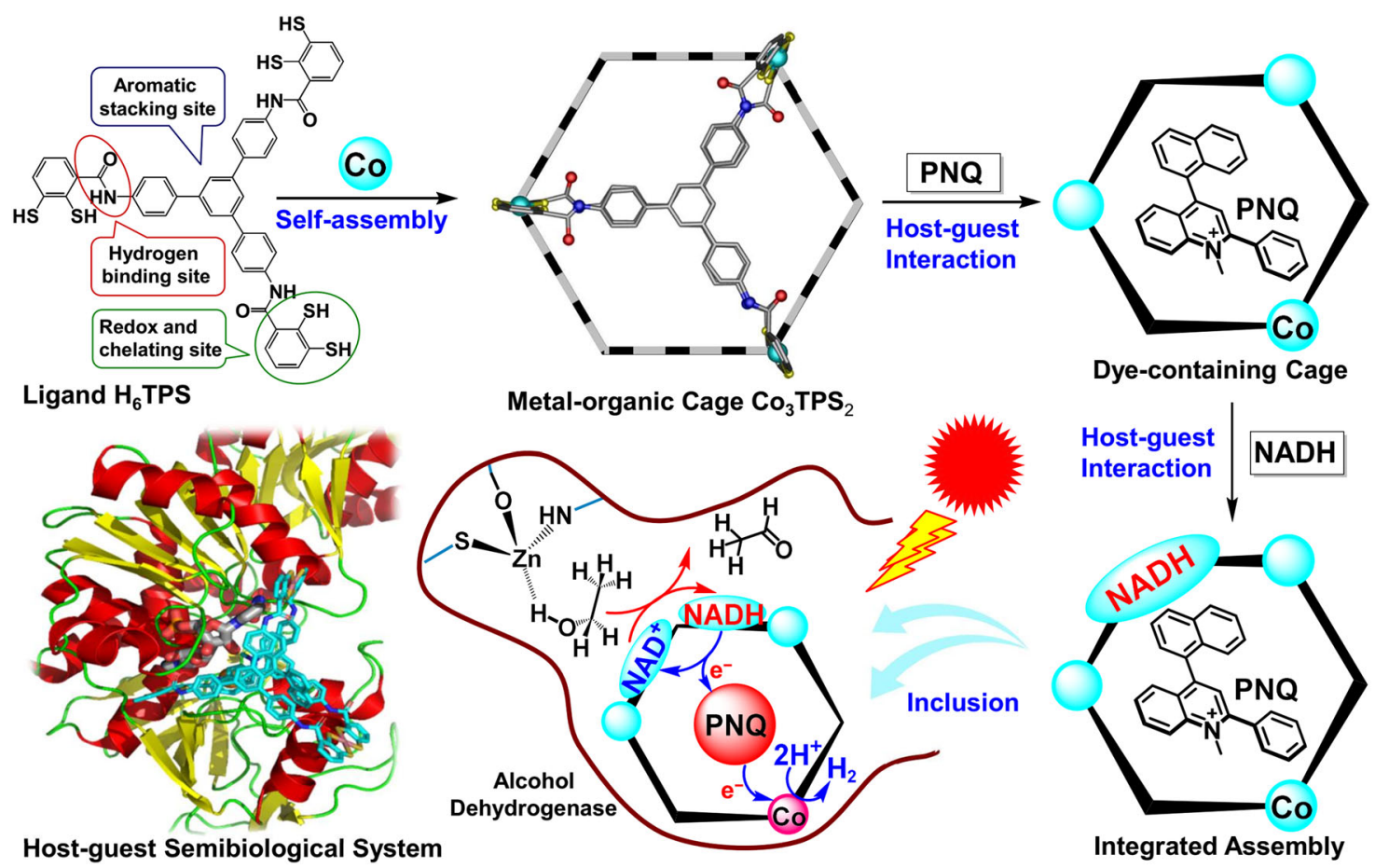

Fig. 1 Schematic of the combination of artificial and natural enzymatic system. Construction of the molecular triangular prism $\mathrm{Co}_{3} \mathbf{T P S}_{2}$, the dyecontaining cage, the $\mathrm{NADH}$-dye-cage ternary supramolecular system, and the host-guest semibiological system comprising metal-organic cage $\mathrm{CO}_{3} \mathbf{T P S}_{2}$ and natural enzyme $A D H$ via non-covalent interactions, representing the assumed major binding conformation of the cage in the ADH enzymatic pocket from the docking study and the potential communication between artificial proton reduction and enzymatic alcohol dehydrogenation via the $N A D^{+} / N^{\prime} A D$ couple.

$6.5 \mathrm{mM}$ p-toluenesulfonic acid, therefore, the overpotential of $\mathrm{Co}_{3} \mathrm{TPS}_{2}$ could be estimated to approximately $0.16 \mathrm{~V}$ using the method of Evans ${ }^{42,43}$, which is comparable to that of the reported cobalt dithiolene-containing catalysts (Supplementary Fig. 15) ${ }^{34}$. These electrochemical experiments indicated that the cobalt dithiolene functionalized $\mathrm{Co}_{3}$ TPS 2 still maintains intrinsic redox activity of the cobalt dithiolene species, and the noninnocent nature of the dithiolene moiety would allow protonation to take place at either the cobalt metal or sulfur for driving hydrogen production $^{33,41,44}$.

Supramolecular photocatalysis in tandem with enzymes. The artificial hosts featuring individual microenvironment are capable of limiting the supramolecular catalysis inside their pocket while coupling with the reactions outside ${ }^{25}$. Inspired by pioneering work $^{28}$, the positively charged dye PNQ that is capable of driving redox events with its moderate quencher NADH (Supplementary Fig. 9), possesses a size of $8.54 \times 8.38 \AA$ triangular plane which ideally matches the $\mathrm{Co}_{3} \mathrm{TPS}_{2}$ cavity. We anticipated that the $\pi$ electron-rich $\mathrm{Co}_{3}$ TPS $_{2}$ with multiple hydrogen bonding sites was able to co-encapsulate aromatic photosensitizer PNQ and electron donor NADH. The resulting close proximity between PNQ and NADH through host-guest approaches would be conducive to accelerating the photoinduced electron transfer from NADH moieties to the excited state of photosensitizer, giving a long-lived reduced photosensitizer to further reduce the cobalt dithiolene cores on the metal-organic cage for proton reduction and hydrogen evolution ${ }^{45}$.

Photocatalytic attempts for proton reduction half-reaction using supramolecular catalyst $\mathrm{Co}_{3} \mathbf{T P S}(20.0 \mu \mathrm{M})$, photosensitizer PNQ (0.5 mM), and electron donor NADH (2.0 mM) was first explored in $\mathrm{EtOH} / \mathrm{H}_{2} \mathrm{O}(3: 2)$ solution upon the irradiation of
$300 \mathrm{~W}$ Xe lamp, resulting in an average of $40 \mu \mathrm{L}$ hydrogen being produced after $4 \mathrm{~h}$ under optimized conditions (Supplementary Figs. 22-25 and Table 3, entry 1). We noticed that the photocatalysis driven by non-noble homogeneous catalyst $\mathrm{Co}_{3}$ TPS $_{2}$ exhibited similar catalytic conversion to that of noble metal catalytic system with $18 \%$ consumption of electron donors $^{28}$. To the best of our knowledge, this is one of the few homogeneous photocatalytic systems that can use $\mathrm{NADH}$ as a direct electron donor to achieve artificial proton reduction ${ }^{4}$, and this supramolecular catalytic system provides a distinctive approach to graft enzymatic system for light-trapped fuel and chemical conversion in a mild condition.

In order to achieve both photocatalytic hydrogen production and alcohol dehydrogenation at the same location, $\mathrm{ADH}(10$ $\left.\mathrm{U} \mathrm{mL}^{-1}\right)$ and $\mathrm{NAD}^{+}(2.0 \mathrm{mM})$ were employed to replace NADH $(2.0 \mathrm{mM})$ for the photocatalysis in $\mathrm{EtOH} / \mathrm{H}_{2} \mathrm{O}$ (3:2) solution containing PNQ $(0.5 \mathrm{mM})$ and $\mathrm{Co}_{3}$ TPS $2(20.0 \mu \mathrm{M})$. Noteworthily, the simultaneously generated hydrogen, and aldehyde were in a similar amount after $12 \mathrm{~h}$, producing $147 \mu \mathrm{L}$ hydrogen with a turnover number (TON) of 550 with respect to $\mathrm{ADH}$, and 8.38 $\mu$ mol aldehyde with a TON 700 with respect to $\mathrm{ADH}$ (Fig. 3b). This result demonstrated that the hybrid system consisting of metal-organic cages and natural enzymes could perfectly synergistically catalyze the NADH-modified hydrogen evolution and the $\mathrm{NAD}^{+}$-mediated alcohol dehydrogenation. The higher production of aldehyde than that of hydrogen indicated that the coenzyme $\mathrm{NADH}$ played an important role in storing protons and electrons, which eliminated the demand for transferring protons and electrons immediately, endowing the catalytic cycle with redundancy reminiscent of natural photosynthesis (Fig. 3b and Supplementary Fig. 32). In fact, the reaction could be extended up to $42 \mathrm{~h}$ and produced an average yield of $232 \mu \mathrm{L}$ hydrogen with a TON of 875 with respect to $\mathrm{ADH}$, exhibiting a 


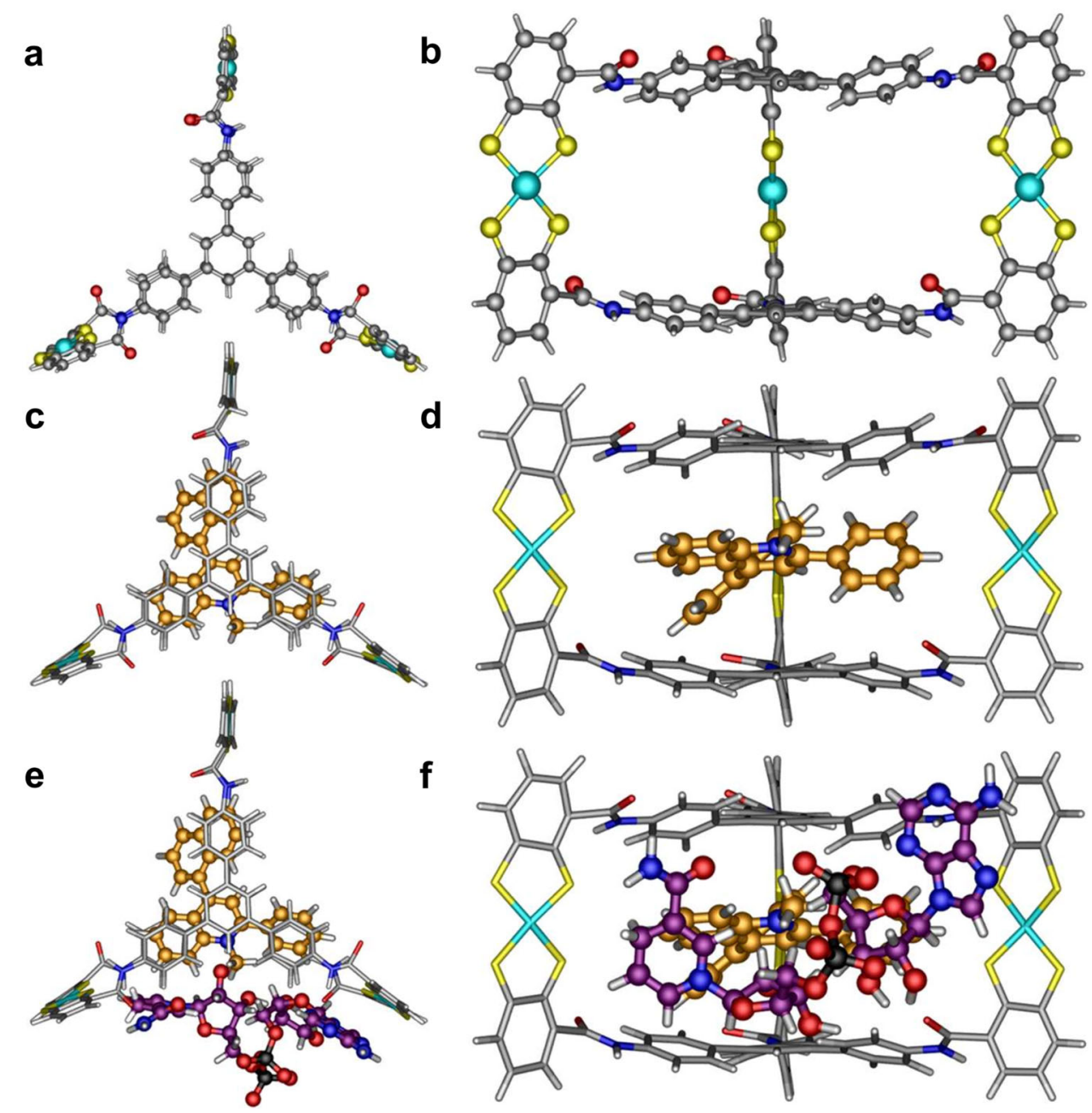

Fig. 2 Structures of the artificial host and the host-guest species. a Crystal structure of the triangular prism $\mathrm{CO}_{3}$ TPS ${ }_{2}$ in top view, showing the large conjugate plane in the ligand $\mathrm{H}_{6}$ TPS. b Crystal structure of the triangular prism $\mathrm{Co}_{3} \mathbf{T P S}$ in main view, showing the coordination geometry of the cobalt dithiolene cores. Co cyan, $\mathrm{S}$ yellow, $\mathrm{N}$ blue, $\mathrm{O}$ red, $\mathrm{C}$ gray, and $\mathrm{H}$ white. $\mathbf{c}$ Top view and $\mathbf{d}$ main view of the theoretical docking study optimized model of $\mathrm{Co}_{3} \mathbf{T P S} \mathbf{S}_{2} \supset \mathbf{P N Q}$, showing the location of the PNQ in the center of $\mathrm{Co}_{3} \mathbf{T P S}$ cavity. e Top view and $\mathbf{f}$ main view of theoretical docking study optimized model of $\mathrm{CO}_{3} \mathbf{T P S}_{2}$ trapping both $\mathbf{P N Q}$ and $\mathrm{NADH}$, showing the close proximity between the redox catalyst, photosensitizer and electron donor.

comparable catalytic activity to those reported similar supramolecular catalytic systems ${ }^{32,46,47}$, while avoiding the use of sacrificial electron donors (Table 1, entry 1). However, the hydrogen production of the enzyme-free photocatalytic system no longer grew with the prolonging of time under the same reaction conditions (Fig. 3c). Control experiments revealed that the absence of any of these individual components led to a failure in hydrogen production (Table 1 , entries $2-5$ ), and the artificial system did not function well in the absence of light (Table 1, entry $6)$. Interestingly, the use of mononuclear compound CoBDT 2 $(60.0 \mu \mathrm{M}$, ensuring the same concentration of cobalt ions; where BDT $=1,2$-benzene-dithiolate $)^{33}$, which resembles a corner of the metal-organic cage $\mathrm{Co}_{3} \mathbf{T P S}$, yielded only $7 \mu \mathrm{L}$ hydrogen following a shorter life of $12 \mathrm{~h}$ under same reaction conditions (Fig. 3b), despite the fact that the redox potential $(-0.56 \mathrm{~V} \mathrm{vs.} \mathrm{Ag/}$ $\mathrm{AgCl}$ ) of the electroactive $\mathrm{CoBDT}_{2}$ is identical to that of $\mathrm{Co}_{3} \mathbf{T P S}_{2}$ (Fig. 3a and Supplementary Figs. 16, 17). Notably, the presence of $\mathrm{CoBDT}_{2}$ also dramatically inhibited the production of aldehyde (Fig. $3 \mathrm{~b}$ and Supplementary Fig. 31), which might be due to the inert binding of $\mathrm{CoBDT}_{2}$ to $\mathrm{ADH}$ (Supplementary Fig. 21). These results demonstrated the ability of supramolecular catalysts to synergistically catalyze with natural enzymes in an efficient and compatible way, achieving a redox-neutral catalysis different from

\begin{tabular}{|c|c|c|c|c|c|}
\hline Entry & Catalyst & PNQ (mM) & $\mathrm{NAD}^{+}(\mathrm{mM})$ & $\begin{array}{l}\text { ADH } \\
\left(\mathrm{U} \mathrm{mL}^{-1}\right)\end{array}$ & $\begin{array}{l}\mathbf{H}_{2} \\
(\mu L)\end{array}$ \\
\hline 1 & $\mathrm{CO}_{3} \mathbf{T P S}_{2}$ & 0.5 & 2.0 & 10 & 232 \\
\hline 2 & - & 0.5 & 2.0 & 10 & 0 \\
\hline 3 & $\mathrm{Co}_{3} \mathbf{T P S} \mathbf{S}_{2}$ & - & 2.0 & 10 & 0 \\
\hline 4 & $\mathrm{CO}_{3} \mathbf{T P S}_{2}$ & 0.5 & - & 10 & 0 \\
\hline 5 & $\mathrm{Co}_{3} \mathbf{T P S}_{2}$ & 0.5 & 2.0 & - & 0 \\
\hline $6^{a}$ & $\mathrm{CO}_{3} \mathbf{T P S}_{2}$ & 0.5 & 2.0 & 10 & 0 \\
\hline $7^{b}$ & $\mathrm{Co}_{3} \mathbf{T P S}_{2}$ & 0.5 & 2.0 & 10 & 41 \\
\hline
\end{tabular}

Reaction conditions: $\mathrm{EtOH} / \mathrm{H}_{2} \mathrm{O}(\mathrm{v}: \mathrm{v}=3: 2, \mathrm{pH} 4.5)$, catalyst $(20.0 \mu \mathrm{M}), \mathrm{Xe} 300 \mathrm{~W}, 42 \mathrm{~h}$. The amount of hydrogen was determined by GC with an external standard method. aln the absence of light.

bln the presence of inhibitor DTQ $(0.1 \mathrm{M})$.

traditional ternary hydrogen evolution systems ${ }^{33,41}$. Moreover, an inhibition experiment was further carried out by adding a nonreactive species, 1,1-dimethyl-1,2,3,4-tetrahydroquinolinium salts (DTQ $^{48}$, to suggest that the fine synergy of multiple electron transfer steps was realized by supramolecular host rather than a 

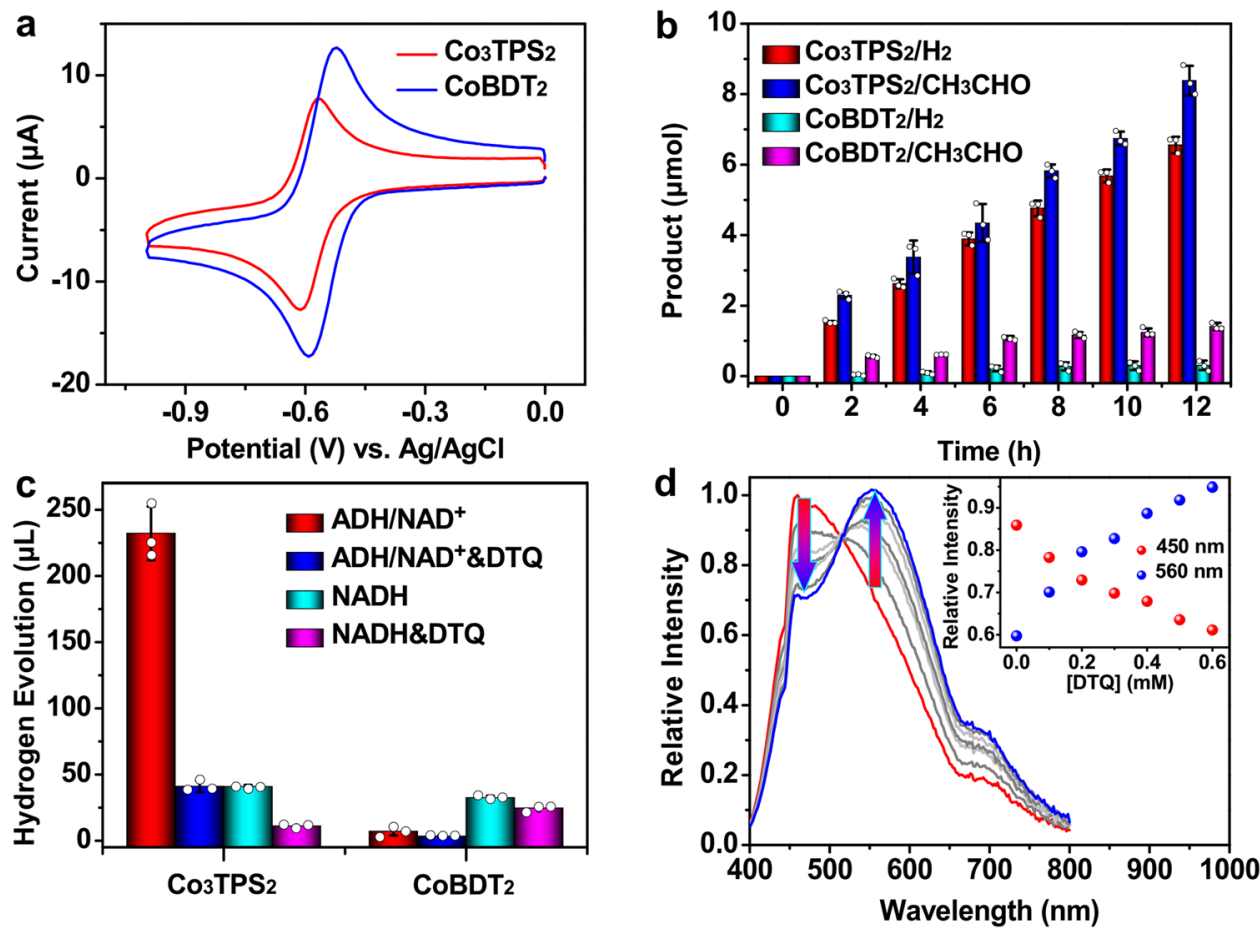

Fig. 3 Catalytic properties of cobalt dithiolene-embedded catalysts. a Cyclic voltammograms of the catalysts ( $0.1 \mathrm{mM}$ ) containing tetrabutylammonium hexafluorophosphate $\left(\mathrm{TBAPF}_{6}, 0.1 \mathrm{M}\right)$ with a scan rate of $100 \mathrm{mV} \mathrm{s}{ }^{-1}$ in DMF. b Light-driven alcohol splitting with PNQ (0.5 mM), NAD+ (2.0 mM), ADH $\left(10 \cup \mathrm{mL}^{-1}\right)$ and redox catalysts $\left(20.0 \mu \mathrm{M}\right.$ for $\mathrm{Co}_{3} \mathbf{T P S}_{2}$ or $60.0 \mu \mathrm{M}$ for $\mathrm{CoBDT}_{2}$, ensuring the same concentration of cobalt ions) in EtOH/H $\mathrm{O}(3: 2, \mathrm{pH}$ 4.5) for $12 \mathrm{~h}$. c Control experiment in EtOH/ $\mathrm{H}_{2} \mathrm{O}(3: 2, \mathrm{pH} 4.5)$ containing PNQ (0.5 mM), redox catalysts (20.0 $\mu \mathrm{M}$ for Co $\mathbf{T P S}_{2}$ or $60.0 \mu \mathrm{M}$ for $\mathrm{CoBDT}_{2}$ ) and $\mathrm{NADH}(2.0 \mathrm{mM})$ or NAD ${ }^{+}(2.0 \mathrm{mM})$ with $\mathrm{ADH}\left(10 \mathrm{U} \mathrm{mL}^{-1}\right)$, in the presence or absence of DTQ (0.1 M) within a $42 \mathrm{~h}$ period. Data points and error bars in $\mathbf{b}$ and $\mathbf{c}$ represent the mean \pm s.d. of three independent experiments. d Luminescence spectra family of PNQ (0.1 mM), Co $\mathbf{T P S} \mathbf{S}_{2}(0.1 \mathrm{mM})$ and $\mathrm{NADH}(0.1 \mathrm{mM})$ in $\mathrm{EtOH} / \mathrm{H}_{2} \mathrm{O}(3: 2)$ upon the addition of DTQ. The inset shows the changes at 450 and $560 \mathrm{~nm}$.

normal homogeneous manner. We speculated that the cation DTQ, which is similar in configuration to the photosensitizer PNQ, could compete to occupy the cavity of $\mathrm{Co}_{3} \mathbf{T P S}$, thereby blocking the orderly photoinduced electron transfer within metalorganic cage ${ }^{32}$. As expected, the addition of DTQ $(0.1 \mathrm{M})$ into the optimal reaction system resulted in an effective quenching of the catalysis and gave only $17 \%$ hydrogen yield of the original system (Fig. $3 \mathrm{c}$ and Table 1, entry 7). These results indicated that the preorganization effect of the host-guest system created an isolated catalytic microenvironment ${ }^{16}$, and the formation of localized catalysis allowed the photocatalysis to not interfere with the reactions outside metal-organic cage, which was essential for coupling enzymatic reactions with benign compatibility ${ }^{13}$.

Changing the $\mathrm{ADH}$ concentration showed that the initial rate of hydrogen production grew linearly with increasing $\mathrm{ADH}$ (from 2 to $10 \mathrm{U} \mathrm{mL}^{-1}$ ), indicating that increasing $\mathrm{ADH}$ increased the more conversion of $\mathrm{NAD}^{+}$to $\mathrm{NADH}$, which effectively supplied the protons and electrons needed for photocatalytic proton reduction (Fig. 4a and Supplementary Fig. 26). Increasing NAD ${ }^{+}$ from $1.0 \mathrm{mM}$ to $2.0 \mathrm{mM}$ improved the amount of hydrogen production from 140 to $232 \mu \mathrm{L}$ (Fig. $4 \mathrm{~b}$ and Supplementary Fig. 27), indicating that a high coenzyme load promoted proton and electron capture during alcohol dehydrogenation. The formation of host-guest species, $\mathrm{Co}_{3} \mathbf{T P S}_{2} \supset \mathbf{P N Q}$, that serve as catalytic machines for proton reduction was verified by the linear increase seen in initial turnover frequency when $\mathrm{Co}_{3} \mathbf{T P S}_{2}$ was increased from $10.0 \mu \mathrm{M}$ to $20.0 \mu \mathrm{M}$ (Fig. $4 \mathrm{c}$ and Supplementary Fig. 28). When PNQ concentration was varied while maintaining the other parameters at a constant level (Fig. 4d and Supplementary Fig. 29), the impact of the amount of PNQ on overall catalysis was not significant compared to that of $\mathrm{Co}_{3} \mathrm{TPS}_{2}$, implying that $\mathrm{Co}_{3} \mathbf{T P S}_{2} \supset$ PNQ played a dominant role in reaction acceleration, rather than PNQ itself $^{32}$. Therefore, appropriately increasing catalyst content and reducing the photosensitizer amount, based on the original system, and performing photocatalysis with $\mathrm{ADH}\left(10 \mathrm{U} \mathrm{mL}^{-1}\right), \mathrm{NAD}^{+}$ $(2.0 \mathrm{mM})$, PNQ $(0.25 \mathrm{mM})$, and $\mathrm{Co}_{3}$ TPS $2(40.0 \mu \mathrm{M})$ resulted in a higher yield amounting to $296 \mu \mathrm{L}$ hydrogen with a TON of 1125 with respect to $\mathrm{ADH}$, and $19.2 \mu \mathrm{mol}$ aldehyde. In this case, the yield of $\mathrm{H}_{2}$ was up to $132 \%$ (based on the concentration of coenzyme couple) and the conversion of $\mathrm{NAD}^{+}$to NADH based on the production of aldehyde was estimated to $192 \%$. Significantly, all corresponding kinetic curves of supramolecular catalysis in collaboration with enzymes showed pseudo-zeroorder kinetic behavior during the initial stages of reactions, and the initial rates of the reaction generally satisfied a Lineweaver-Burk plot with a concentration of $\mathrm{NAD}^{+}$or $\mathrm{Co}_{3} \mathbf{T P S}_{2}$ (Supplementary Fig. 30), further suggesting that both the metalorganic cage and coenzyme were located at $\mathrm{ADH}$ catalytic pocket for in situ catalysis, and this host-guest approach was able to transform the alcohol dehydrogenase into the alcohol lyases and created a continuously operating photosynthesis 26,27 .

Characterization of host-guest interactions. To further understand the role of host-guest chemistry, the ESI-MS spectrum, isothermal titration calorimetry (ITC) essay, UV-Vis absorption spectra, circular dichroism (CD) spectra, fluorescence spectra, gel filtration chromatography, dynamic light scattering (DLS) analyses, and theoretical docking study were employed to provide insight into the host-guest interactions between functional components. The host-guest mode between $\mathrm{Co}_{3} \mathbf{T P S}_{2}$ and PNQ 

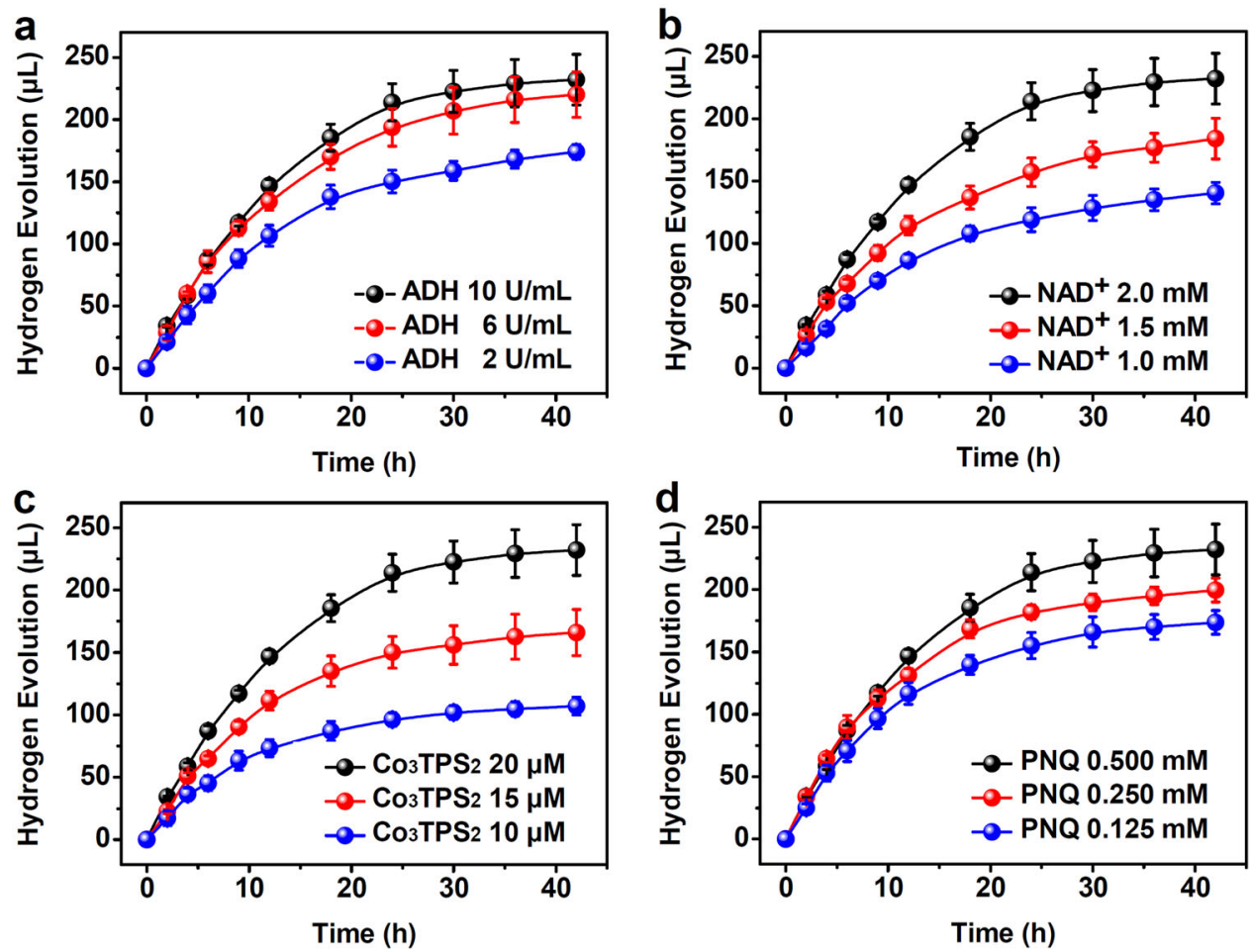

Fig. 4 Kinetics of the photocatalytic hydrogen evolution from alcohol dehydrogenation. Hydrogen evolution in $\mathrm{EtOH} / \mathrm{H}_{2} \mathrm{O}(3: 2, \mathrm{pH} 4.5)$ a as a function of the concentration of $\mathrm{ADH}_{\text {with NAD }}+(2.0 \mathrm{mM}), \mathrm{Co}_{3} \mathbf{T P S}_{2}(20.0 \mu \mathrm{M})$ and PNQ $(0.5 \mathrm{mM})$ remaining fixed; $\mathbf{b}$ as a function of the concentration of NAD ${ }^{+}$ with $\mathrm{ADH}\left(10 \mathrm{U} \mathrm{mL}{ }^{-1}\right), \mathrm{CO}_{3} \mathbf{T P S}_{2}(20.0 \mu \mathrm{M})$ and $\mathbf{P N Q}(0.5 \mathrm{mM})$ remaining fixed; $\mathbf{c}$ as a function of the concentration of $\mathrm{Co}_{3} \mathbf{T P S}_{2}$ with $\mathrm{ADH}\left(10 \mathrm{U} \mathrm{mL}^{-1}\right)$, $\mathrm{NAD}^{+}(2.0 \mathrm{mM})$ and $0.5 \mathrm{mM}$ PNQ remaining fixed; $\mathbf{d}$ as a function of the concentration of PNQ with ADH $\left.\left(10 \mathrm{U} \mathrm{mL}^{-1}\right), \mathrm{NAD}^{+}(2.0 \mathrm{mM})\right)$ and $\mathrm{Co}_{3} \mathbf{T P S}_{2}$ $(20.0 \mu \mathrm{M})$ remaining fixed. Data points and error bars represent the mean \pm s.d. of three independent experiments in all figures.

was first identified. Upon addition of PNQ $(1.0 \mathrm{mM})$ into the solution of $\mathrm{Co}_{3} \mathbf{T P S}_{2}(1.0 \mathrm{mM})$, a sharp peak corresponding to $\left[\mathrm{Co}_{3}(\mathrm{TPS})_{2} \cdot \mathbf{P N Q}\right]^{2-}$ at $\mathrm{m} / z=1111.5117$ was observed in ESI-MS spectrum (Supplementary Fig. 3), suggesting that PNQ could be included into $\mathrm{Co}_{3} \mathbf{T P S}_{2}$ to form 1:1 host-guest species ${ }^{29}$. ITC assay of $\mathrm{Co}_{3} \mathrm{TPS}_{2}$ upon the addition of PNQ gave a disassociation constant $K_{\mathrm{d} 1}$ measuring $6.99 \mu \mathrm{M}$, wherein the large change in Gibbs free energy $(\Delta G)$ was calculated as $-29.43 \mathrm{~kJ} \mathrm{~mol}^{-1}$, showing the considerable affinity between the host $\mathrm{Co}_{3} \mathbf{T P S}_{2}$ and the guest PNQ molecule (Fig. 5a and Supplementary Fig. 18) ${ }^{49}$.

Subsequently, the integration of $\mathrm{Co}_{3} \mathrm{TPS}_{2}, \mathbf{P N Q}$, and NADH into one working module was explored. ITC measurment upon addition of coenzyme NADH into the solution containing both $\mathrm{Co}_{3} \mathrm{TPS}_{2}$ and PNQ yielded a $K_{\mathrm{d} 2}$ of $33.32 \mu \mathrm{M}$, and a $\Delta G$ of $-25.56 \mathrm{~kJ} \mathrm{~mol}^{-1}$ (Fig. 5a and Supplementary Fig. 19), suggesting the formation of an integrated supramolecular assembly in solution with a potential 1:1:1 stoichiometry 26,50 . This integrated binding was further supported by UV-Vis absorption and fluorescence spectra titration. The addition of NADH $(0.1 \mathrm{mM})$ into a EtOH/ $\mathrm{H}_{2} \mathrm{O}$ (3:2) solution containing both $\mathrm{Co}_{3} \mathbf{T P S}_{2}$ $(0.1 \mathrm{mM})$ and PNQ $(0.1 \mathrm{mM})$ resulted in several isosbestic points in the absorption band fitting well with the 1:1 binding model at $660 \mathrm{~nm}$ (Fig. 5b and Supplementary Fig. 5) ${ }^{51}$, and caused obvious emission quenching at $560 \mathrm{~nm}$ along with the emergence of a new blue-shifted peak at $450 \mathrm{~nm}$ agreeing with the non-linear Hill plot (Fig. 5c) ${ }^{52,53}$, further confirming that recognition and assembly actually occurred when the coenzyme NADH encountered in a $\mathrm{Co}_{3} \mathrm{TPS}_{2} / \mathbf{P N Q}$ microenvironment. Although further forming multinary assembly with more $\mathrm{NADH}$ molecules was not observed, this possibility could not be ruled out.
Docking calculations suggested that the aromatic plane of PNQ, which fell on the center of the host cavity due to aromatic stacking interactions ${ }^{54}$, highly overlapped the large conjugate plane of $\mathrm{Co}_{3} \mathrm{TPS}_{2}$ (Fig. 2c, d and Supplementary Fig. 34). NADH was in close proximity to the window of $\mathrm{Co}_{3} \mathrm{TPS}_{2}$ due to multiple hydrogen bonds yielding a calculated $\Delta G$ of $-24.58 \mathrm{~kJ} \mathrm{~mol}^{-1}$, a value which was in line with that estimated by the ITC test. This result suggested that spontaneous molecular behavior ensured a short distance and allowed direct communication between the nicotinamide moiety of electron donor NADH and photosensitizer PNQ, providing convenience for artificial catalytic system and natural enzyme to form integrated assembly (Fig. 2e, f and Supplementary Fig. 35$)^{50}$.

Importantly, the addition of DTQ into the $\mathrm{Co}_{3} \mathrm{TPS}_{2} / \mathrm{PNQ} /$ NADH system resulted in an emission recovery at $560 \mathrm{~nm}$ with a decrease in signal intensity at $450 \mathrm{~nm}$ (Fig. 3d), reflecting that the formation of supramolecular host-guest assembly led to the drastic retrenchment in terms of the distance between functional components, and the passivation behavior of the photocatalysis after adding inhibitor DTQ could be attributed to the destruction of the $\mathrm{Co}_{3} \mathrm{TPS}_{2} / \mathrm{PNQ} / \mathrm{NADH}$ host-guest architecture through DTQ's occupation in the cavity of $\mathrm{Co}_{3} \mathbf{T P S}_{2}$. The close proximity of NADH to PNQ enabled the completion of a pseudointramolecular electron transfer process from NADH via PNQ to the cobalt dithiolene moieties on the cage at a rate faster than the diffusion of $\mathrm{NADH}^{29}$, which was intuitively validated via electron paramagnetic resonance spectra (Supplementary Fig. 11). Control experiments showed that when the addition of NADH $(0.1 \mathrm{mM})$ into a EtOH/ $\mathrm{H}_{2} \mathrm{O}$ (3:2) solution containing both $\mathrm{CoBDT}_{2}(0.3 \mathrm{mM})$ and PNQ $(0.1 \mathrm{mM})$ triggered a quenching following linear Stern-Volmer fitting (Supplementary Fig. 10) ${ }^{33}$. 

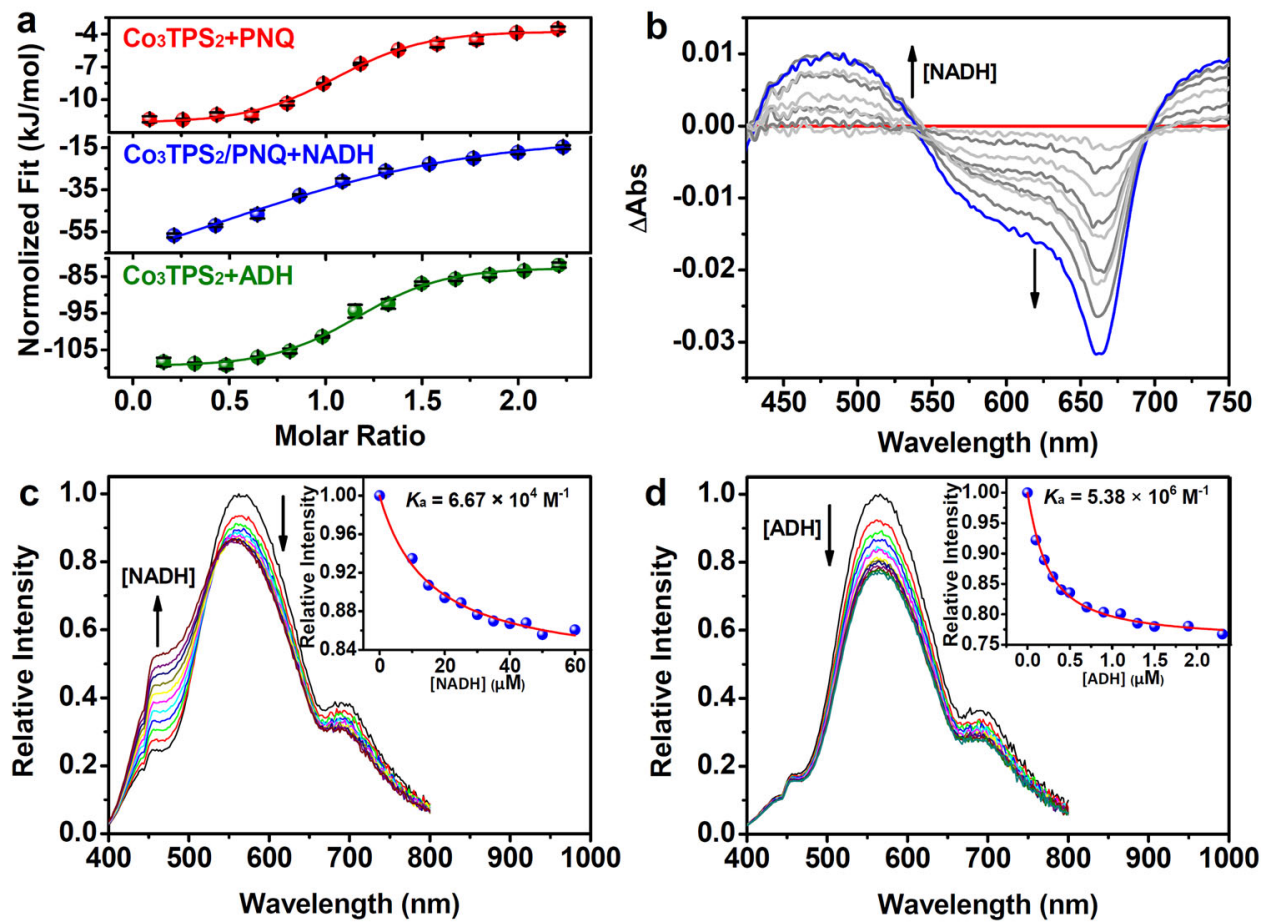

Fig. 5 Characterization of host-guest interactions between $\mathbf{C o}_{\mathbf{3}} \mathbf{T P S _ { 2 }}$ and PNQ or NADH. a Isothermal titration calorimetry tests of $\mathrm{Co}_{3} \mathbf{T P S} \mathrm{S}_{2}$ upon addition of PNQ (red) and ADH (green), and of the mixture of $\mathrm{Co}_{3} \mathbf{T} \mathbf{P} \mathbf{S}_{2}$ and $\mathbf{P N Q}$ upon addition of NADH (blue). Error bars are the calculated standard error from the curve fit. $\mathbf{b} U V$-Vis absorption difference spectra of PNQ $(0.1 \mathrm{mM})$ and $\mathrm{Co}_{3} \mathbf{T P S}_{2}(0.1 \mathrm{mM})$ in EtOH/ $\mathrm{H}_{2} \mathrm{O}(3: 2)$ upon the addition of $\mathrm{NADH}$. $\mathbf{c}$ Luminescence spectra family of PNQ $(0.1 \mathrm{mM})$ and $\mathrm{Co}_{3} \mathbf{T P S}_{2}(0.1 \mathrm{mM})$ in EtOH/ $\mathrm{H}_{2} \mathrm{O}(3: 2)$ upon the addition of NADH. Inset: Hill plot of the fluorescence intensity with a non-linear fitting at $560 \mathrm{~nm}$ (1:1 binding model). d Luminescence spectra family of PNQ $(0.1 \mathrm{mM})$ and $\mathrm{Co}_{3} \mathbf{T P S}(0.1 \mathrm{mM})$ in EtOH/ $\mathrm{H}_{2} \mathrm{O}$ (3:2) upon the addition of $A D H$. Inset: Hill plot of the fluorescence intensity with a non-linear fitting at $560 \mathrm{~nm}$ (1:1 binding model).

This intermolecular collision behavior indicated that the catalysis in $\mathrm{CoBDT}_{2} / \mathbf{P N Q} / \mathrm{NADH}$ catalytic system was a normal homogeneous reaction different from the $\mathrm{Co}_{3} \mathrm{TPS}_{2} / \mathrm{PNQ} / \mathrm{NADH}$ supramolecular system. These results indicated that the metalorganic host $\mathrm{Co}_{3} \mathbf{T P S}_{2}$ was able to integrate artificial catalytic components through host-guest interactions, which was beneficial to constraining an effective proton reduction inside the supramolecular host, and the formation of regional cooperation and division in catalysis was beneficial to joining outer enzymatic reactions for a redox-neutral artificial photosynthesis.

The host-guest relationship between artificial catalyst and natural enzyme was further considered. Both UV-Vis and CD spectra showed the characteristic peaks attributable to $\mathrm{ADH}$ were basically maintained after adding the cage $\mathrm{Co}_{3} \mathbf{T P S}_{2}$ (Supplementary Fig. 6). The intensity of $\mathrm{Co}_{3} \mathbf{T P S}_{2}(10.0 \mu \mathrm{M})$ at $300 \mathrm{~nm}$ decreased linearly when treated with a small amount of $\mathrm{ADH}$ (total $0.65 \mathrm{nM}$ ) (Supplementary Fig. 7), and the related difference spectra of UV-Vis absorption revealed a significant spectra changes centered at $268 \mathrm{~nm}$ from an initial linear growth to almost unchanged (Supplementary Fig. 8), which could be interpreted as the steady conversion of $\mathrm{ADH}$ to $\mathrm{ADH} \supset \mathrm{Co}_{3} \mathrm{TPS}_{2}$ complex ${ }^{26,55,56}$. Luminescence titration of dye-containing cage $\left(0.1 \mathrm{mM} \mathrm{Co} \mathrm{TPS}_{2}\right.$ and PNQ) upon the addition of $\mathrm{ADH}$ in EtOH/ $\mathrm{H}_{2} \mathrm{O}$ (3:2) exhibited significant quenching of luminescent intensity at $560 \mathrm{~nm}$, and the titration curve coinciding with the non-linear Hill plot (Fig. 5d). The observed quenching behavior was probably attributed to the capture of the dye-containing cage by $\mathrm{ADH}$ catalytic pocket via non-covalent interactions similar to the reported artificial host-guest system ${ }^{29}$. Elaborate calculations of the thermodynamics of $\mathrm{Co}_{3} \mathbf{T P S}_{2}$ binding to $\mathrm{ADH}$ were conducted using ITC evaluation (Fig. 5a and Supplementary Fig. 20), which yielded a disassociation constant $K_{\mathrm{d} 3}$ of $0.23 \mu \mathrm{M}$ accompanied with a large $\Delta G$ of $-37.90 \mathrm{~kJ} \mathrm{~mol}^{-1}$, reflecting the high affinity between the cage $\mathrm{Co}_{3} \mathbf{T P S}_{2}$ and enzyme ADH supported by supramolecular interactions ${ }^{26,57}$. Gel filtration chromatography showed that the sample of $\mathrm{ADH}$ with $\mathrm{Co}_{3} \mathbf{T P S}_{2}$ emerged a new peak with a shorter retention time than that of $\mathrm{ADH}$, implying that $\mathrm{Co}_{3} \mathrm{TPS}_{2}$ bound to $\mathrm{ADH}$ giving a larger hydrodynamic radius (Supplementary Fig. 12a). The DLS measurement of $\mathrm{ADH}$ exhibited a sharp size-distribution peak and presented an average hydrodynamic radius of $\sim 6.9 \mathrm{~nm}$, while an average hydrodynamic radius of $\sim 7.3 \mathrm{~nm}$ after adding the cage $\mathrm{Co}_{3} \mathbf{T P S}_{2}$ (Supplementary Fig. 12b). Theoretical docking study revealed that the dye-containing cage was capable of binding to the ADH catalytic pocket and burying its active cobalt dithiolene moiety into $\mathrm{ADH}$ to form a working module (Supplementary Fig. 36). The random binding model manifested that the cage binding to the $\mathrm{ADH}$ catalytic pocket was the major binding conformation with a higher binding energy, which might benefit from the suitable opening and abundant non-covalent interaction site of the enzymatic pocket (Supplementary Fig. 37). In addition, the coenzyme NADH was locked in the enzymatic pocket, serving as a communicator to couple artificial and natural enzymes. The generated $\mathrm{NAD}^{+}$could directly participate in the enzymatic alcohol dehydrogenation, eliminating the diffusion process of coenzyme in the bulk solution and leading to a redox-neutral photosynthesis system (Supplementary Fig. 37) 26,27,58. These findings indicated that the careful orchestration of a dyecontaining metal-organic cage into the enzymes catalytic pocket allowed the in situ communication between the abiotic 


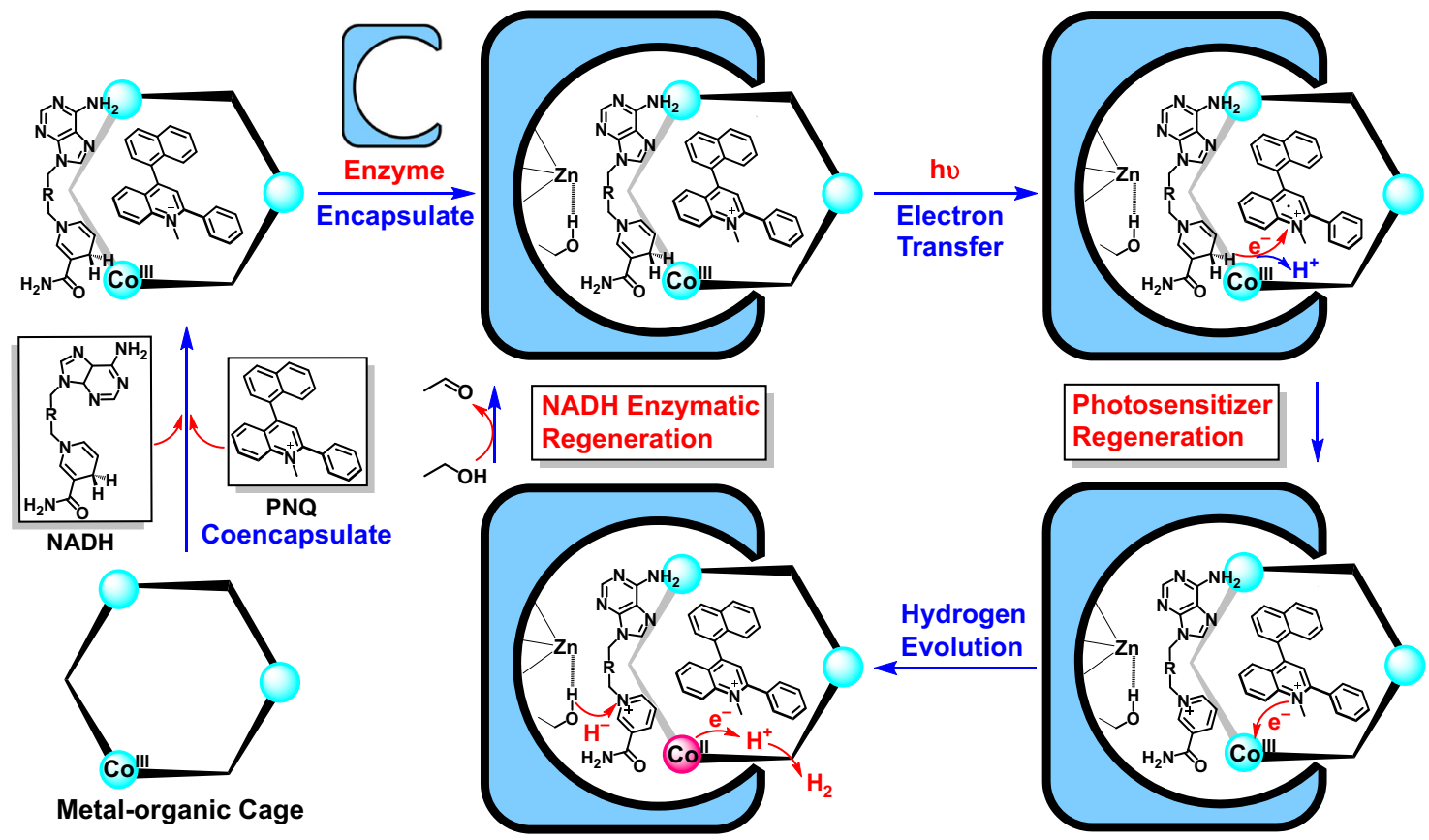

Fig. 6 Proposed mechanisms for abiotic-biotic coupled system in photocatalytic alcohol splitting. Schematic of semibiological supramolecular system for solar alcohol splitting showed that the coenzyme locked in the ADH catalytic pocket joined artificial photocatalysis with enzymatic reactions in situ.

and biotic systems through coenzymes. In this situation, the transport of electrons and matters during photosynthesis was strengthened in a closed loop of electrons and protons, which deserved better synthetic sequences with finer synergy.

Proposed mechanisms of catalysis. This light-driven supramolecular host-guest semibiological system was well modified for the simultaneous combination of dye-mediated artificial catalysis with a biotic catalysis at the pocket of ADH enzyme, which allowed the $\mathrm{NADH}$-mediated photocatalytic proton reduction in tandem with $\mathrm{NAD}^{+}$-mediated enzymatic alcohol dehydrogenation in situ (Fig. 6). The well-designed artificial metal-organic host, which possesses cobalt dithiolene catalytic cores on the skeleton and stacking interaction sites in the hydrophobic pocket and multiple hydrogen bonding sites at the opening windows, could simultaneously trap a photosensitizer and coenzyme to restraint the photoinduced hydrogen production from alcohol dehydrogenation inside its pocket. The close proximity between electron donors, electron acceptors, and catalytic cores guided a pseudointramolecular electron transfer from NADH moieties to the excited photosensitizer, and then to further reduce the cobalt dithiolene core on the metal-organic cage for proton reduction. With the intervention of enzymes, the artificial host coerced the entire photocatalytic proton reduction half-reaction into the ADH catalytic pocket and formed a superstructure containing both artificial and natural catalytic system. In this case, the transfer of matters and energy between the abiotic and biotic catalytic modules could be enhanced through close contact, which avoided the diffusion of coenzymes and the expense of sacrificial reagents. The coenzyme $\mathrm{NADH} / \mathrm{NAD}^{+}$regenerated in redox catalysis was used as a direct electron/proton supply in situ for the next catalytic cycle, enabling a smooth switching between the abiotic photocatalysis and established enzymatic reactions. In the meanwhile, the inherent confined effects provided by both artificial host and enzyme allowed the formation of relatively independent catalytic processes, eliminating inherent mutual interference between the abiotic and biotic systems and promoting the formation of a continuously running redoxneutral photosynthesis system.

\section{Discussion}

In summary, a redox-active metal-organic cage $\mathrm{Co}_{3} \mathrm{TPS}_{2}$ as a hydrogenase analog was embedded into the catalytic pocket of natural enzyme $\mathrm{ADH}$ through supramolecular interactions for solar alcohol splitting. The abundant non-covalent interaction sites in the artificial host allowed it to form an integrated host-guest species with a photosensitizer and an electron donor, constraining the photocatalytic hydrogen production from alcohol dehydrogenation inside the supramolecular host. The direct proton and electron delivery at close range between the two redox catalytic cycles provided positive feedback to the alcohol dehydrogenation processes. The attempt to associate artificial enzyme with non-photoactive natural enzyme in a host-guest approach achieved the optimized allocation of matter and energy by forming regional cooperation and division and insured electron transfer more efficient and controllable, illuminating the superiority of this supramolecular host-guest approach for redoxneutral artificial photosynthesis and providing a potential way to reduce carbon dioxide and even nitrogen.

\section{Methods}

General methods and materials. ${ }^{1} \mathrm{H}$ NMR dates were collected on a Bruker $400 \mathrm{M}$ spectrometer with chemical shifts reported as ppm (in DMSO- $d_{6}$ or $\mathrm{CDCl}_{3}$, TMS as internal standard). Elemental analyses of $\mathrm{C}, \mathrm{H}$, and $\mathrm{N}$ were performed on a Vario EL III elemental analyzer. ESI mass spectra dates were collected on a HPLC-Q-Tof MS spectrometer using acetonitrile as mobile phase. ITC essays were performed on a Nano ITC (TA Instruments Inc., Waters LLC). UV-Vis spectra were performed on a HP 8453 spectrometer. Fluorescent spectra were performed on Edinburgh FS-1000. CD spectra were measured on a JASCO J-810 spectropolarimeter. DLS measurements were performed on Malvern Zetasizer Nano ZS90 analyzer. EPR spectra were measured on a Bruker E500 spectrometer. Electrochemical measurements were carried out under $\mathrm{Ar}$ at room temperature and performed on a ZAHNER ENNIUM electrochemical workstation with a conventional three-electrode system with an $\mathrm{Ag} / \mathrm{AgCl}$ electrode as a reference electrode, a platinum silk with $0.5 \mathrm{mM}$ diameter as a counter electrode, and glassy carbon electrode as a working electrode. Gel filtration chromatography was performed on AKTA purifier 100 using a Sephadex G-75 gel sieving column, UV-Vis detector (detection wavelength $280 \mathrm{~nm}$ ), $1 \times \mathrm{PBS}$ as mobile phase. Unless stated otherwise, all chemicals were of reagent grade quality obtained from commercial sources, biomaterial ADH from Saccharomyces cerevisiae was purchased from Sigma-Aldrich. Solvents were dried by standard methods and freshly distilled prior to use. All synthesis operations were carried out under an atmosphere of dry argon using Schlenk and vacuum techniques. The photosensitizer PNQ and catalyst 
$\mathrm{CoBDT}_{2}$ were synthesized according to the reported procedures by Fukuzumi ${ }^{28}$ and Eisenberg ${ }^{33}$, respectively. Ligand $\mathrm{H}_{6}$ TPS was synthesized similar to the reported procedures $32,59,60$.

Synthesis of $\mathbf{H}_{\mathbf{6}}$ TPS precursor. Freshly prepared 2,3-bis(isopropylthio)benzoyl chloride was dissolved in THF $(20 \mathrm{~mL})$ and this solution was added to a solution of $4,4^{\prime}, 4^{\prime \prime}$-triaminotriphenyl-benzene $(0.5 \mathrm{~g}, 1.30 \mathrm{mmol})$ and $\mathrm{NEt}_{3}(2.0 \mathrm{mmol})$ in THF $(40 \mathrm{~mL})$ at $0{ }^{\circ} \mathrm{C}$. Then, the reaction mixture was stirred for $12 \mathrm{~h}$ at ambient temperature. Subsequently, insoluble material was removed by filtration and the solvent was removed from the filtrate under vacuum. The pure product was obtained after washing with diethyl ether. Yield: $1.4 \mathrm{~g}, 92 \% .{ }^{1} \mathrm{H}$ NMR $\left(\mathrm{CDCl}_{3}\right.$, $400 \mathrm{MHz}, \mathrm{ppm}$ ): $\delta 9.07$ (s, 3H; NH), 7.80-7.64 (m, 18H; ArH), 7.42-7.35 (m, 6H; $\mathrm{ArH}), 7.11(\mathrm{~d}, J=8.8 \mathrm{~Hz}, 6 \mathrm{H} ; \mathrm{ArH}), 3.55-3.41\left(\mathrm{~m}, 6 \mathrm{H} ;\left(\mathrm{CH}_{3}\right)_{2}\right), 1.41(\mathrm{~d}, J=6.7 \mathrm{~Hz}$, $\left.18 \mathrm{H} ; \mathrm{CH}_{3}\right), 1.24\left(\mathrm{~d}, J=6.7 \mathrm{~Hz}, 18 \mathrm{H} ; \mathrm{CH}_{3}\right) .{ }^{13} \mathrm{C}$ NMR $\left(\mathrm{CDCl}_{3}, 101 \mathrm{MHz}, \mathrm{ppm}\right): \delta$ 166.1 146.0, 142.0, 141.8, 137.6, 137.2, 129.2, 128.9, 128.5, 128.0, 126.4, 124.5, 120.3, 41.4, 36.3, 23.1, 22.7. ESI-MS calcd for $\mathrm{C}_{63} \mathrm{H}_{69} \mathrm{~N}_{3} \mathrm{O}_{3} \mathrm{~S}_{6}: 1107.37$, found $1108.37[\mathrm{M}+\mathrm{H}]+, 1130.36[\mathrm{M}+\mathrm{Na}]^{+}$. Elemental analysis calcd for $\mathrm{C}_{63} \mathrm{H}_{69} \mathrm{~N}_{3} \mathrm{O}_{3} \mathrm{~S}_{6}$ : H, 6.27; C, 68.25; N, 3.79\%; found: H, 6.34; C, 67.66; N, 3.75\%.

Preparation of $\mathrm{CO}_{\mathbf{3}} \mathbf{T P S}_{\mathbf{2}}$. Freshly distilled THF $(20 \mathrm{~mL})$ was added to a mixture of precursor $(387.6 \mathrm{mg}, 0.35 \mathrm{mmol})$, sodium $(181.1 \mathrm{mg}, 7.85 \mathrm{mmol})$, and naphthalene ( $336.5 \mathrm{mg}, 2.60 \mathrm{mmol}$ ), and the reaction was stirred for $12 \mathrm{~h}$ at $25^{\circ} \mathrm{C}$. Subsequently, methanol $(5.0 \mathrm{~mL})$ was added to remove unreacted sodium and reaction solvents were removed under vacuum. The solid residue was dissolved in degassed water and the resulting solution was washed three times with degassed diethyl ether $(3 \times 20 \mathrm{~mL})$. The aqueous solution was filtered and acidified with $\mathrm{HCl}(37 \%)$ to give a white precipitate, $\mathrm{H}_{6}$ TPS, which was used directly to stir with $\mathrm{NaOH}(85.6 \mathrm{mg}, 2.14 \mathrm{mmol})$ and $\mathrm{Co}\left(\mathrm{BF}_{4}\right)_{2} \cdot 6 \mathrm{H}_{2} \mathrm{O}(183.9 \mathrm{mg}, 0.54 \mathrm{mmol})$ in a DMF solution $(30 \mathrm{~mL})$ for $12 \mathrm{~h}$. Then, $\mathrm{NEt}_{4} \mathrm{Cl}(89.5 \mathrm{mg}, 0.54 \mathrm{mmol})$ was added to this solution and stir for another $4 \mathrm{~h}$. Then, the solution was poured into diethyl ether for a dark blue precipitate. The solid was collected and redissolved in DMF, and the dark blue crystals of $\mathrm{Co}_{3} \mathbf{T P S}_{2}$ suitable for single-crystal X-ray diffraction were obtained by diffusing diethyl ether into the DMF solution, yield: $51 \%$. Elemental analysis calcd for $\mathrm{Co}_{3}\left(\mathrm{C}_{45} \mathrm{H}_{27^{-}}\right.$ $\left.\mathrm{N}_{3} \mathrm{O}_{3} \mathrm{~S}_{6}\right)_{2} \cdot\left(\mathrm{NC}_{8} \mathrm{H}_{20}\right)_{3} \cdot\left(\mathrm{C}_{3} \mathrm{H}_{7} \mathrm{NO}\right): \mathrm{H}, 5.21 ; \mathrm{C}, 60.03$; N, 5.98\%; found: $\mathrm{H}, 5.31 ; \mathrm{C}, 59.96$ N, 6.21\%. ESI-MS: $m / z=625.6254\left[\mathrm{Co}_{3}(\text { TPS })_{2}\right]^{3-}, 949.9336\left[\mathrm{NaCo}_{3}(\text { TPS })_{2}\right]^{2-}$.

X-ray crystallography. The intensities of the $\mathrm{Co}_{3} \mathbf{T P S}_{2}$ were collected at $180(2) \mathrm{K}$ on a Bruker SMART APEX CCD diffractometer equipped with graphite monochromated Mo-Ka $(\lambda=0.71073 \AA)$ radiation source and the data were acquired using the SMART and SAINT programs ${ }^{61,62}$. The structure was solved by direct methods and refined on $F^{2}$ by full-matrix least-squares methods with SHELXTL version 5.1 software ${ }^{63}$. In the structural refinement of $\mathrm{Co}_{3} \mathbf{T P S}_{2}$, all the nonhydrogen atoms were refined anisotropically. Hydrogen atoms within the ligand backbones, a DMF molecule, and three $\mathrm{NEt}_{4}{ }^{+}$cations were fixed geometrically at calculated distances and allowed to ride on the parent non-hydrogen atoms. To assist the stability of refinements, two amide groups on the ligands, a DMF molecule, and two $\mathrm{Et}_{4} \mathrm{~N}^{+}$cations were limited to the desired position with rational thermal parameters by several restrains. One methyl on an $\mathrm{Et}_{4} \mathrm{~N}^{+}$cation, and a carbon atom and nitrogen atom on the DMF were disordered into two parts with s.o.f of each part being refined using free variables. The thermal parameters on adjacent atoms in all $\mathrm{Et}_{4} \mathrm{~N}^{+}$cations, a DMF molecule, and some parts of ligands were restrained to be similar. In addition, the SQUEEZE subroutine in PLATON was used for refinements ${ }^{64}$.

Crystal data of $\mathrm{Co}_{3}$ TPS $_{2}: \mathrm{Co}_{3}\left(\mathrm{C}_{45} \mathrm{H}_{27} \mathrm{~N}_{3} \mathrm{O}_{3} \mathrm{~S}_{6}\right)_{2} \cdot 3 \mathrm{NC}_{8} \mathrm{H}_{20} \cdot \mathrm{C}_{3} \mathrm{H}_{7} \mathrm{NO} \cdot 4.5 \mathrm{H}_{2} \mathrm{O}$, $M=2421.81$, Triclinic, space group $P-1$, black blue rod, $a=12.8740(12)$, $b=27.316(3), c=27.453(4) \AA, \alpha=119.649(3), \beta=98.301(6), \gamma=94.063(4)$, $V=8187.8(15) \AA^{3}, Z=2, D c=0.982 \mathrm{~g} \mathrm{~cm}^{-3}, \mu(\mathrm{Mo}-\mathrm{K} \alpha)=0.499 \mathrm{~mm}^{-1}$, $T=180(2)$ K. 28,559 unique reflections $\left[R_{\text {int }}=0.1044\right]$. Final $R_{1}$ [with $I>2 \sigma(I)]=0.1074, w R_{2}$ (all data) $=0.2388$ for the data collected. CCDC number 2042990 .

General methods for theoretical 'docking study'. Docking calculations were performed with the AutoDock program 4.2. The $\mathrm{Co}_{3} \mathbf{T P S}_{2}, \mathbf{P N Q}$, and NADH were downloaded from the CCDC database. The structure of enzyme alcohol dehydrogenase was downloaded from the Protein Data Bank (PDB) database (PDB code: 5ENV). The cage $\mathrm{Co}_{3} \mathbf{T P S}_{2}$ was used to perform the docking calculation after energy minimization. The models of the enzyme were refined by removing hydrogen atoms. Polar hydrogens were then added, followed by the assignment of Kollman charges, fragmental volumes, and atomic solvation parameters to adhesive by means of AutoDock Tools. For the ligand, the molecule was refined by removing and subsequently adding hydrogen atoms in a similar manner to that for adhesive. Next, Gasteiger partial charges were assigned to the ligands, and nonpolar hydrogens were merged. All torsions were allowed to rotate during docking. The Lamarckian genetic algorithm was used to determine the appropriate binding positions, orientations, and conformations of the ligands. Default parameters were used, except for the number of generations which was set to 300 . The blind docking strategy was used with a $50 \AA \times 78 \AA \times 114 \AA$ grid box which ensured sufficient spaced to cover the entire surface of the enzyme. The Lamarckian genetic algorithm was chosen with default parameters except for the number of generations, which was set to 100 for more accurate docking results. The best docking mode of the host-guest complex was chosen based on the binding energy score, clustering, and chemical reasonableness.

General methods for photocatalysis. General method for photocatalytic proton reduction. Varying amounts of the catalyst and PNQ were added into an EtOH/ $\mathrm{H}_{2} \mathrm{O}$ solution ( $\mathrm{v}: \mathrm{v}=3: 2, \mathrm{pH} 4.5,5.0 \mathrm{~mL}$ ) containing NADH with a magnetic stir bar. The flask was sealed with a septum and protected from air by Ar. The samples were irradiated by a $300 \mathrm{~W}$ Xenon lamp. The reaction was maintained at $25^{\circ} \mathrm{C}$ by using a water filter to absorb heat. The general method for photocatalytic alcohol splitting. Varying amounts of the catalyst, ADH and PNQ were added into an $\mathrm{EtOH} / \mathrm{H}_{2} \mathrm{O}$ solution $(\mathrm{v}: \mathrm{v}=3: 2, \mathrm{pH} 4.5,5.0 \mathrm{~mL})$ containing $\mathrm{NAD}^{+}$with a magnetic stir bar. The flask was sealed with a septum and protected from air by Ar. The samples were irradiated by a $300 \mathrm{~W}$ Xenon lamp. The reaction was maintained at $25^{\circ} \mathrm{C}$ by using a water filter to absorb heat. The generated hydrogen was characterized by GC $7890 \mathrm{~T}$ instrument analysis using a $5 \AA$ molecular sieve column, thermal conductivity detector, and argon used as carrier gas. The amount of hydrogen generated was determined by external standard method ${ }^{65}$. The generated aldehyde was characterized by an Agilent 6890N GC system using a FFAP capillary column, flame ionization detector, and nitrogen used as carrier gas. The amount of aldehyde generated was determined by external standard method ${ }^{17,66}$.

\section{Data availability}

The X-ray crystallographic coordinates for the structures reported in this article have been deposited at the Cambridge Crystallographic Data Centre under the deposition numbers CCDC 2042990. The data can be obtained free of charge from the Cambridge Crystallographic Data Centre via http://www.ccdc.cam.ac.uk/data_request/cif. Enzyme $\mathrm{ADH}$ structure data with the accession code 5ENV was downloaded from the PDB database via https://www.rcsb.org/. All other data supporting the findings of this study are available within the article and its Supplementary Information files or from the corresponding author upon request. A reporting summary for this article is available. Source data are provided with this paper.

Received: 12 January 2021; Accepted: 28 July 2021; Published online: 24 August 2021

\section{References}

1. Burgener, S., Luo, S., McLean, R., Miller, T. E. \& Erb, T. J. A roadmap towards integrated catalytic systems of the future. Nat. Catal. 3, 186-192 (2020).

2. Schmermund, L. et al. Photo-biocatalysis: biotransformations in the presence of light. ACS Catal. 9, 4115-4144 (2019).

3. Ye, R., Zhao, J., Wickemeyer, B. B., Toste, F. D. \& Somorjai, G. A. Foundations and strategies of the construction of hybrid catalysts for optimized performances. Nat. Catal. 1, 318-325 (2018).

4. Lee, S. H., Choi, D. S., Kuk, S. K. \& Park, C. B. Photobiocatalysis: activating redox enzymes by direct or indirect transfer of photoinduced electrons. Angew. Chem. Int. Ed. 57, 7958-7985 (2018).

5. Guo, J. et al. Light-driven fine chemical production in yeast biohybrids. Science 362, 813-816 (2018).

6. Reisner, E. When does organic photoredox catalysis meet artificial photosynthesis? Angew. Chem. Int. Ed. 58, 3656-3657 (2019).

7. Dogutan, D. K. \& Nocera, D. G. Artificial photosynthesis at efficiencies greatly exceeding that of natural photosynthesis. Acc. Chem. Res. 52, 3143-3148 (2019).

8. Trincado, M., Banerjeea, D. \& Grützmacher, H. Molecular catalysts for hydrogen production from alcohols. Energy Environ. Sci. 7, 2464-2503 (2014)

9. Dołęga, A. Alcohol dehydrogenase and its simple inorganic models. Coord. Chem. Rev. 254, 916-937 (2010).

10. Walsh, C. T., Tu, B. P. \& Tang, Y. Eight kinetically stable but thermodynamically activated molecules that power cell metabolism. Chem. Rev. 118, 1460-1494 (2018).

11. Zhang, P. et al. Electron bifurcation: thermodynamics and kinetics of twoelectron brokering in biological redox chemistry. Acc. Chem. Res. 50, 2410-2417 (2017).

12. Morra, S. \& Pordea, A. Biocatalyst-artificial metalloenzyme cascade based on alcohol dehydrogenase. Chem. Sci. 9, 7447-7454 (2018).

13. Wang, Z. J., Clary, K. N., Bergman, R. G., Raymond, K. N. \& Toste, F. D. A supramolecular approach to combining enzymatic and transition metal catalysis. Nat. Chem. 5, 100-103 (2013).

14. Hammarström, L. Accumulative charge separation for solar fuels production: coupling light-induced single electron transfer to multielectron catalysis. Acc. Chem. Res. 48, 840-850 (2015).

15. McSkimming, A. \& Colbran, S. B. The coordination chemistry of organohydride donors: new prospects for efficient multi-electron reduction. Chem. Soc. Rev. 42, 5439-5488 (2013). 
16. Wang, Q. et al. Self-assembled nanospheres with multiple endohedral binding sites pre-organize catalysts and substrates for highly efficient reactions. Nat Chem. 8, 225-230 (2016).

17. Liu, K., Yuan, C., Zou, Q., Xie, Z. \& Yan, X. A Self-assembled zinc/cystinebased chloroplast mimics capable of photoenzymatic reactions for sustainable fuel synthesis. Angew. Chem. Int. Ed. 56, 7876-7880 (2017).

18. Proctor, R. S. J., Colgan, A. C. \& Phipps, R. J. Exploiting attractive noncovalent interactions for the enantioselective catalysis of reactions involving radical intermediates. Nat. Chem. 12, 990-1004 (2020).

19. Ward, M. D., Hunter, C. A. \& Williams, N. H. Coordination cages based on bis(pyrazolylpyridine) ligands: structures, dynamic behavior, guest binding, and catalysis. Acc. Chem. Res. 51, 2073-2082 (2018).

20. Fang, Y. et al. Catalytic reactions within the cavity of coordination cages. Chem. Soc. Rev. 48, 4707-4730 (2019).

21. Kaphan, D. M., Levin, M. D., Bergman, R. G., Raymond, K. N. \& Toste, F. D. A supramolecular microenvironment strategy for transition metal catalysis. Science 350, 1235-1238 (2015).

22. Takezawa, H., Shitozawa, K. \& Fujita, M. Enhanced reactivity of twisted amides inside a molecular cage. Nat. Chem. 12, 574-578 (2020).

23. Yamashina, M. et al. An antiaromatic-walled nanospace. Nature 574, 511-515 (2019).

24. Jing, X., He, C., Zhao, L. \& Duan, C. Photochemical properties of host-guest supramolecular systems with structurally confined metal-organic capsules. Acc. Chem. Res. 52, 100-109 (2019).

25. Jin, Y., Zhang, Q., Zhang, Y. \& Duan, C. Electron transfer in the confined environments of metal-organic coordination supramolecular systems. Chem. Soc. Rev. 49, 5561-5600 (2020).

26. Zhao, L., Cai, J., Li, Y., Wei, J. \& Duan, C. A host-guest approach to combining enzymatic and artificial catalysis for catalyzing biomimetic monooxygenation. Nat. Commun. 11, 2903-2913 (2020).

27. Jiao, Y., Zhang, L., Gao, X., Si, W. \& Duan, C. A cofactor-substrate-based supramolecular fluorescent probe for the ultrafast detection of nitroreductase under hypoxic conditions. Angew. Chem. Int. Ed. 59, 6021-6027 (2020).

28. Yamada, Y., Miyahigashi, T., Kotani, H., Ohkubo, K. \& Fukuzumi, S. Photocatalytic hydrogen evolution under highly basic conditions by using $\mathrm{Ru}$ nanoparticles and 2-phenyl-4-(1-naphthyl) quinolinium ion. J. Am. Chem. Soc. 133, 16136-16145 (2011).

29. Jing, X., He, C., Yang, Y. \& Duan, C. A metal-organic tetrahedron as a redox vehicle to encapsulate organic dyes for photocatalytic proton reduction. J. Am. Chem. Soc. 137, 3967-3974 (2015).

30. Chen, S. et al. A metal-organic cage incorporating multiple light harvesting and catalytic centres for photochemical hydrogen production. Nat. Commun. 7, 13169-13176 (2016).

31. Lubitz, W., Ogata, H., Rüdiger, O. \& Reijerse, E. Hydrogenases. Chem. Rev. 114, 4081-4148 (2014)

32. Cai, J. et al. Negatively charged metal-organic hosts with cobalt dithiolene species: improving PET processes for light-driven proton reduction through host-guest electrostatic interactions. Chem. Commun. 55, 8524-8527 (2019).

33. McNamara, W. R. et al. A cobalt-dithiolene complex for the photocatalytic and electrocatalytic reduction of protons. J. Am. Chem. Soc. 133, 15368-15371 (2011).

34. Clough, A. J., Yoo, J. W., Mecklenburg, M. H. \& Marinescu, S. C. Twodimensional metal-organic surfaces for efficient hydrogen evolution from water. J. Am. Chem. Soc. 137, 118-121 (2015).

35. Kumazawa, K., Biradha, K., Kusukawa, T., Okano, T. \& Fujita, M. Multicomponent assembly of a pyrazine-pillared coordination cage that selectively binds planar guests by intercalation. Angew. Chem. Int. Ed. 42 3909-3913 (2003).

36. Nakamura, T., Ube, H. \& Shionoya, M. Silver-mediated formation of a cofacial porphyrin dimer with the ability to intercalate aromatic molecules. Angew. Chem. Int. Ed. 52, 12096-12100 (2013).

37. McKee, V., Nelson, J. \& Town, R. M. Caged oxoanions. Chem. Soc. Rev. 32, 309-325 (2003).

38. Takezawa, H., Tabuchi, R., Sunohara, H. \& Fujita, M. Confinement of watersoluble cationic substrates in a cationic molecular cage by capping the portals with tripodal anions. J. Am. Chem. Soc. 142, 17919-17922 (2020).

39. Sepehrpour, H., Saha, M. L. \& Stang, P. J. Fe-Pt twisted heterometallic bicyclic supramolecules via multicomponent self-assembly. J. Am. Chem. Soc. 139, 2553-2556 (2017).

40. Jiao, J. et al. Design and self-assembly of hexahedral coordination cages for cascade reactions. Nat. Commun. 9, 4423-4430 (2018).

41. McNamara, W. R. et al. Cobalt-dithiolene complexes for the photocatalytic and electrocatalytic reduction of protons in aqueous solutions. Proc. Natl Acad. Sci. USA 109, 15594-15599 (2012).

42. Felton, G. A. N., Glass, R. S., Lichtenberger, D. L. \& Evans, D. H. Iron-only hydrogenase mimics. Thermodynamic aspects of the use of electrochemistry to evaluate catalytic efficiency for hydrogen generation. Inorg. Chem. 45, 9181-9184 (2006).
43. Helm, M. L., Stewart, M. P., Bullock, R. M., DuBois, M. R. \& DuBois, D. L. A synthetic nickel electrocatalyst with a turnover frequency above 100,000 s-1 for $\mathrm{H}_{2}$ production. Science 333, 863-866 (2011).

44. Solis, B. H. \& Hammes-Schiffer, S. Computational study of anomalous reduction potentials for hydrogen evolution catalyzed by cobalt dithiolene complexes. J. Am. Chem. Soc. 134, 15253-15256 (2012).

45. Fukuzumi, S., Hong, D. \& Yamada, Y. Bioinspired photocatalytic water reduction and oxidation with earth-abundant metal catalysts. J. Phys. Chem. Lett. 4, 3458-3467 (2013)

46. He, C. et al. A photoactive basket-like metal-organic tetragon worked as an enzymatic molecular flask for light driven $\mathrm{H}_{2}$ production. Chem. Commun. 49 , 627-629 (2013).

47. Yang, L., Jing, X., He, C., Chang, Z. \& Duan, C. Redox-active $\mathrm{M}_{8} \mathrm{~L}_{6}$ cubic hosts with tetraphenylethylene faces encapsulate organic dyes for light-driven $\mathrm{H}_{2}$ production. Chem. Eur. J. 22, 18107-18114 (2016).

48. Paras, N. A., Simmons, B. \& MacMillan, D. W. C. A process for the rapid removal of dialkylamino-substituents from aromatic rings. Application to the expedient synthesis of (R)-tolterodine. Tetrahedron 65, 3232-3238 (2009).

49. Huang, G., Wang, S., Ke, H., Yang, L. \& Jiang, W. Selective recognition of highly hydrophilic molecules in water by endo-functionalized molecular tubes. J. Am. Chem. Soc. 138, 14550-14553 (2016).

50. Sawada, T., Yoshizawa, M., Sato, S. \& Fujita, M. Minimal nucleotide duplex formation in water through enclathration in self-assembled hosts. Nat. Chem. 1, 53-56 (2009).

51. Thordarson, P. Determining association constants from titration experiments in supramolecular chemistry. Chem. Soc. Rev. 40, 1305-1323 (2011).

52. Zeng, L. et al. A paper-based chemosensor for highly specific, ultrasensitive, and instantaneous visual detection of toxic phosgene. Chem. Commun. 55, 13753-13756 (2019)

53. Connors, K. A. Binding Constants (John Wiley, New York, 1987).

54. Neel, A. J., Hilton, M. J., Sigman, M. S. \& Toste, F. D. Exploiting non-covalent $\pi$ interactions for catalyst design. Nature 543, 637-646 (2017).

55. $\mathrm{Li}, \mathrm{Z}$. et al. An interprotein $\mathrm{Co}-\mathrm{S}$ coordination complex in the $\mathrm{B}_{12}$-trafficking pathway. J. Am. Chem. Soc. 142, 16334-16345 (2020).

56. Guengerich, F. P., Child, S. A., Barckhausen, I. R. \& Goldfarb, M. H. Kinetic evidence for an induced-fit mechanism in the binding of the substrate camphor by cytochrome P450 cam. ACS Catal. 11, 639-649 (2021).

57. Zhang, P. et al. The third generation of artificial dye-decolorizing peroxidase rationally designed in myoglobin. ACS Catal. 9, 7888-7893 (2019).

58. Liu, P. et al. MDM2-Associated clusterization-triggered emission and apoptosis induction effectuated by a theranostic spiropolymer. Angew. Chem. Int. Ed. 59, 8435-8439 (2020).

59. Birkmann, B., Fröhlich, R. \& Hahn, F. E. Assembly of a tetranuclear host with a tris(benzene-o-dithiolato) ligand. Chem. Eur. J. 15, 9325-9329 (2009).

60. Okamura, T., Kunisue, K., Omi, Y. \& Onitsuka, K. Strong NH...S hydrogen bonds in molybdoenzyme models containing anilide moieties. Dalton Trans. 42, 7569-7578 (2013)

61. SMART. Data Collection Software (Version 5.629) (Bruker AXS Inc., Madison WI, 2003).

62. SAINT. Data Reduction Software (Version 6.45) (Bruker AXS Inc., Madison, WI, 2003).

63. Sheldrick, G. M. SHELXTL97, Program for Crystal Structure Solution (University of Göttingen: Göttingen, Germany, 1997).

64. Spek, A. L. Single-crystal structure validation with the program PLATON. J. Appl. Cryst. 36, 7-13 (2003).

65. Dong, J. et al. Promoting effect of electrostatic interaction between a cobalt catalyst and a xanthene dye on visible-light-driven electron transfer and hydrogen production. J. Phys. Chem. C. 115, 15089-15096 (2011).

66. Simon, T. et al. Redox shuttle mechanism enhances photocatalytic $\mathrm{H}_{2}$ generation on Ni-decorated CdS nanorods. Nat. Mater. 13, 1013-1018 (2014)

\section{Acknowledgements}

This work was supported by the National Natural Science Foundation of China (Nos. 21820102001, 21861132004, and 21890381) and the Fundamental Research Funds for the Central Universities (DUT20TD101).

\section{Author contributions}

J.C., L.Z., C.H., and C.D. conceived the project and designed the experiments. J.C. carried out the main experiments, collected and interpreted the data. Y.L prepared the ligand. J.C., L.Z., and C.H. solved and refined the X-ray single-crystal structures. L.Z., C.H., and C.D. contributed materials and analysis tools. J.C., L.Z., and C.D. co-wrote the paper. All authors discussed the results and commented on the manuscript.

\section{Competing interests}

The authors declare no competing interests. 


\section{Additional information}

Supplementary information The online version contains supplementary material available at https://doi.org/10.1038/s41467-021-25362-4.

Correspondence and requests for materials should be addressed to L.Z. or C.D.

Peer review information Nature Communications thanks Michael Ward and other, anonmyous, reveiwers for their contributions to the peer reivew of this work. Peer review reports are available.

Reprints and permission information is available at http://www.nature.com/reprints

Publisher's note Springer Nature remains neutral with regard to jurisdictional claims in published maps and institutional affiliations. (c) (i) Open Access This article is licensed under a Creative Commons Attribution 4.0 International License, which permits use, sharing, adaptation, distribution and reproduction in any medium or format, as long as you give appropriate credit to the original author(s) and the source, provide a link to the Creative Commons license, and indicate if changes were made. The images or other third party material in this article are included in the article's Creative Commons license, unless indicated otherwise in a credit line to the material. If material is not included in the article's Creative Commons license and your intended use is not permitted by statutory regulation or exceeds the permitted use, you will need to obtain permission directly from the copyright holder. To view a copy of this license, visit http://creativecommons.org/ licenses/by/4.0/.

(C) The Author(s) 2021 